G.A. Karkashadze, L.S. Namazova-Baranova, A.K. Gevorkyan, O.I. Maslova, A.M. Mamed"yarov, N.S. Sergienko, L.A. Osipova, T.Yu. Gogberashvili

Scientific Center of Children's Health, Moscow, Russian Federation

\title{
Outpatient specialized pediatric neurological care appeal incidence: structure and primary regularities
}

\section{Author Affiliation:}

Georgii Archilovich Karkashadze, MD, pediatric neurologist, head of the department of cognitive pediatrics at the research institute of preventive pediatrics and medical rehabilitation of the Scientific Center of Children's Health

Address: 2/2 Lomonosovskiy Av., Moscow, 119991; tel.: +7 (495) 967-14-20; e-mail: kakashadze@,nczd.ru

\section{Article received: 14.04.2014. Accepted for publication: 17.09.2014.}

The article presents an analysis of outpatient specialized neurological care appeals to the consultative-diagnostic center and the neurological pathology structure, as well as age and gender peculiarities of its breakdown. The authors revealed that higher mental dysfunctions are the most widespread. They also provide an analysis of underestimation of separate neurological deviations by parents. The article provides recommendations on outpatient specialized pediatric neurological care delivery optimization.

Keywords: children, outpatient neurological care, pediatric neurological appeal incidence structure, cognitive disorders, speech disorders.

\section{INTRODUCTION}

Neurological care for children of Russia is a pressing task for the national pediatric services [1]. It is, however, tremendously difficult to organize it due to diversity and prevalence of neurological disorders in children. As of now, organization of neurological care is still marked by outdated Soviet traditions, as it was developed in those times. Inconsistence of the out-of-date approaches with the current situations limits the possibilities of neurological care for children. Revised should be the provisions emanating from the idea that specialized care shall be provided exclusively via inpatient care. It is no secret for any expert that any specialized care, which includes neurological care, shall be provided as outpatient care to a maximum extent. Indeed, a multiplicity of centers providing outpatient neurological care for children has been established in Russia in recent years, especially in larger cities [2]. Thereby, functions are distributed within the outpatient care system. Attendances at state-run outpatient clinics are mostly aimed at prophylaxis and selection of candidates for specialized treatment [3]. Specialized outpatient care is provided at diagnostics and treatment centers.

\section{Purpose and methodology of the study}

Given the changes of the neurological care provision structure, we have carried out a study designed to define the patterns of providing specialized outpatient care for children in the modern world. The results of the study will enable the researchers to offer a set of organizational measures for enhancing outpatient neurological care for children in Russia.

The diagnostics center of the Scientific Center of Health of Children has been chosen as the research institution. Neurologists' attendances of 2013 have been analyzed. The purpose of the Center is to provide care in compliance with the obligatory and optional medical insurance programs as well as after fee-based appeals. The patient flow comprises initial hospital care appointments, appointments issued by other medical institutions, and individual appeals. 
Neurological care consists of diagnosing and treating the conditions, which can be effectively treated by means of outpatient care. This can be considered specialized outpatient care. Analysis of such care faithfully reflects the main trends in the neurologic care for children statistics, since it includes finalized diagnoses of pathological conditions and is less oriented at prophylaxispurposed appeals as compared to initial outpatient care.

\section{RESULTS}

Overall, we have analyzed 334 neuropsychology-related appeals by parents. 186 of those were initial appeals, whilst others were follow-up attendances. Subject to analysis were mostly initial appeals, as they provide a more adequate pattern of the general population-based topicality of the issue. Follow-up attendance figures often depend on the specific factors like presence or absence of highly specialized activities. Besides, the same physician may diagnose and treat different conditions with unequal efficiency. Therefore, the figures reflect the topicality of the issue as interpreted under the influence of the local institutional factors and cannot be considered objective in terms of general population-based trend assessment.

\section{The Age-based Distribution of Appeals for Specialized Neurological Care}

Pediatric neurology is characterized by specific manifestations of individual conditions at certain ages. This is why all the appeals were distributed based on the age (pic. 1)

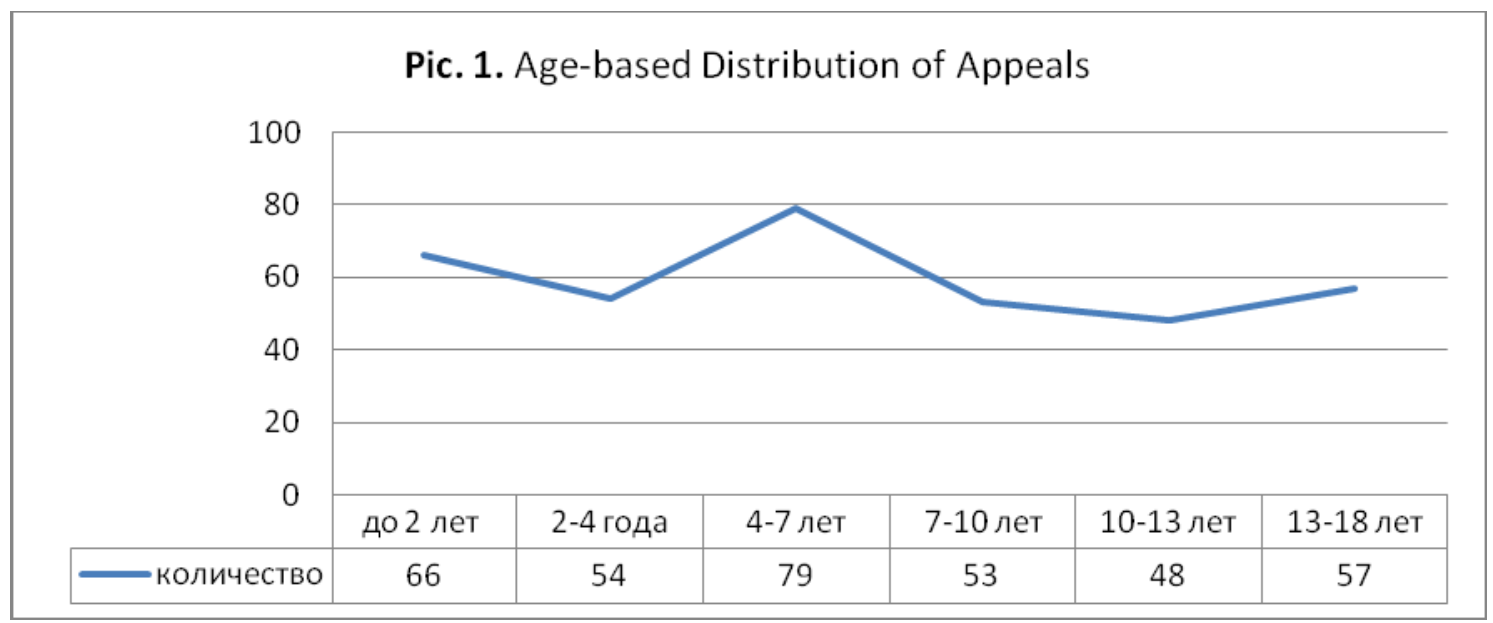

TRANSLATOR'S NOTE: the Russian terms used in the following graphs are translated into English in the table below.

\begin{tabular}{|l|l|}
\hline RUSSIAN & ENGLISH \\
\hline количество & Number \\
\hline до & Less than \\
\hline года & Year(s) \\
\hline лет & Years \\
\hline перв & Initial (appeal) \\
\hline повт & Follow-up (appeal) \\
\hline нарушения поведения и эмоций & Behaviour and emotion disorders \\
\hline нарушения речи & speech disorders \\
\hline другие когнитивные нарушения & Other cognitive disorders \\
\hline головные боли & headaches \\
\hline нарушения сна & sleep disorders \\
\hline неэпилептические пароксизмы & Non-epileptic paroxysms \\
\hline
\end{tabular}




\begin{tabular}{|l|l|}
\hline нарушения мышечного тонуса & muscle tone disorders \\
\hline эпилепсии & Epilepsies \\
\hline церебрастении & Encephalasthenia \\
\hline навязчивые действия & obsessive-compulsive disorders \\
\hline энурез & Enuresis \\
\hline носовые кровотечения & epistaxis \\
\hline здоровы & Healthy \\
\hline мальчики & Boys \\
\hline девочки & Girls \\
\hline патологические моторные феномены и действия & Pathologic motor phenomena \\
\hline нарушения двигательных функций & locomotor functions \\
\hline пароксизмальные состояния & Paroxysmal conditions \\
\hline болевые синдромы & pain syndromes \\
\hline нарушения перцепции и общей активности & Sensing and general activity disorders \\
\hline энкопрез & Encopresis \\
\hline нарушения походки & Gait disorders \\
\hline задержки моторного развития & Motor development delays \\
\hline органические поражения, ДЦП & organic lesions, CCP \\
\hline нарушения мышечного тонуса & muscle tone disorders \\
\hline повторные & Initial (appeals) \\
\hline первичные & Follow-up (appeals) \\
\hline нар-я сна & Sleep disorders \\
\hline
\end{tabular}

As can be seen, the appeals are distributed rather evenly between the age groups. However, preschool children (i.e. 4-7-year-old) group does show a larger number of appeals. At this age, mild cognitive behavioral disorders manifest themselves more clearly, and such disorders are difficult for parents to discover due to uncontrollable behavior of children younger than 3 . This is what makes this age relevant. Besides, neurotic reactions and their manifestations in the form of stuttering and tic disorders first appear at this age, and the issue of enuresis becomes obvious. The parents become more suspicious of neurological ill-being symptoms, especially those related to cognitive activity, before the child starts to attend the school.

However, the appeal distribution per year of life seems more relevant, since age-based groups are divided by unequal intervals. For instance, the 13 to 18 group contains people of five different ages, and $<1$ group contains people of the same age. Analysis of the appeal numbers per year of lifetime reveals that most appeals are made during the first year of life, and the numbers are uniformly reduced with aging (pic. 2).

Therefore, when calculated on the year basis, the preschool group being dominant in terms of appeal numbers has been identified as a delusional phenomenon. Actually, the appeal numbers have a downward trend tied to aging. The most obvious reason therefor, as we think, is not the reduction of prevalence of diseases, but the reasons behind the appeals. At earlier ages, most appeals are prophylactic, thence the larger numbers. In the first years of the child's life, the child's behavior is difficult for the parents to interpret, especially considering speech underdevelopment. With aging, CNS state and general psychics become easier to comprehend, which causes the number of prophylactic appeals to decrease, and the number of appeals reasoned by more topical issues to increase. It can be proven by the age-based analysis of initial and follow-up appeals (pic. 3) 
The high proportion of follow-up appeals indicates a greater proportion of critical chronic conditions. If initial appeals prevail, it points out a greater proportion of mild non-chronic conditions. Based on the obtained data, the\%age of follow-up appeals in the $<1$ and 1 to 4 age groups is not high; however, it increases with aging till the late preschool age, where it makes up for almost a half of all appeals. Such distribution is also observable in the consequent age groups. Therefore, the initial to follow-up appeal ratio implicitly testifies the reasons. In the first years of life, appeals are more prophylaxis-purposed, but in older age groups, they reflect the specific topical issues.
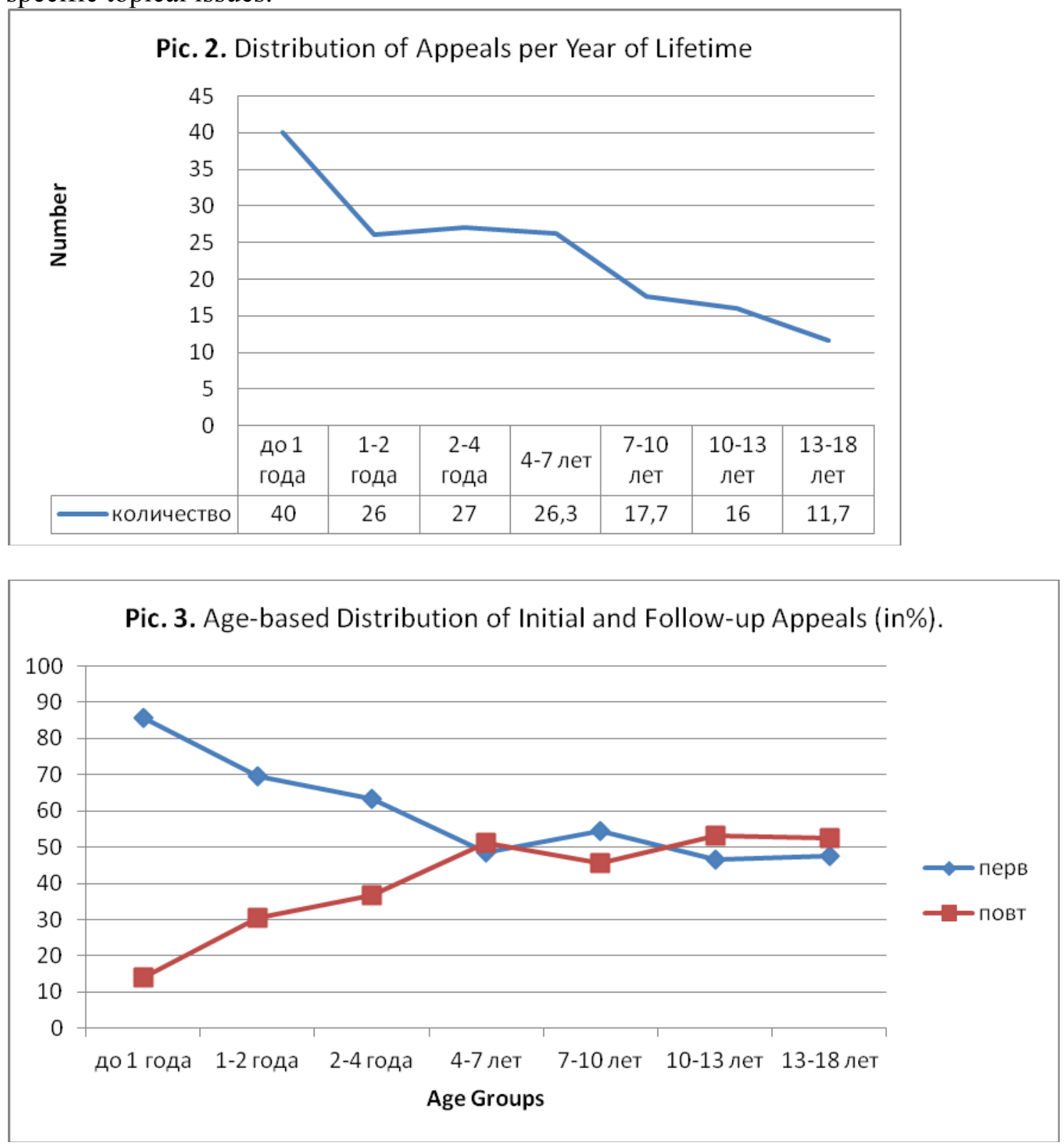


\section{The Gender-based Distribution of Appeals for Specialized Neurological Care}

Boys' aptitude to neurologic disorders is well-known (pic. 4). Our data prove the fact once again. The 228 boys account for $68.2 \%$ of the sample, whilst the 106 girls account only for $31.8 \%$. Age-based gender distribution has certain fluctuations.

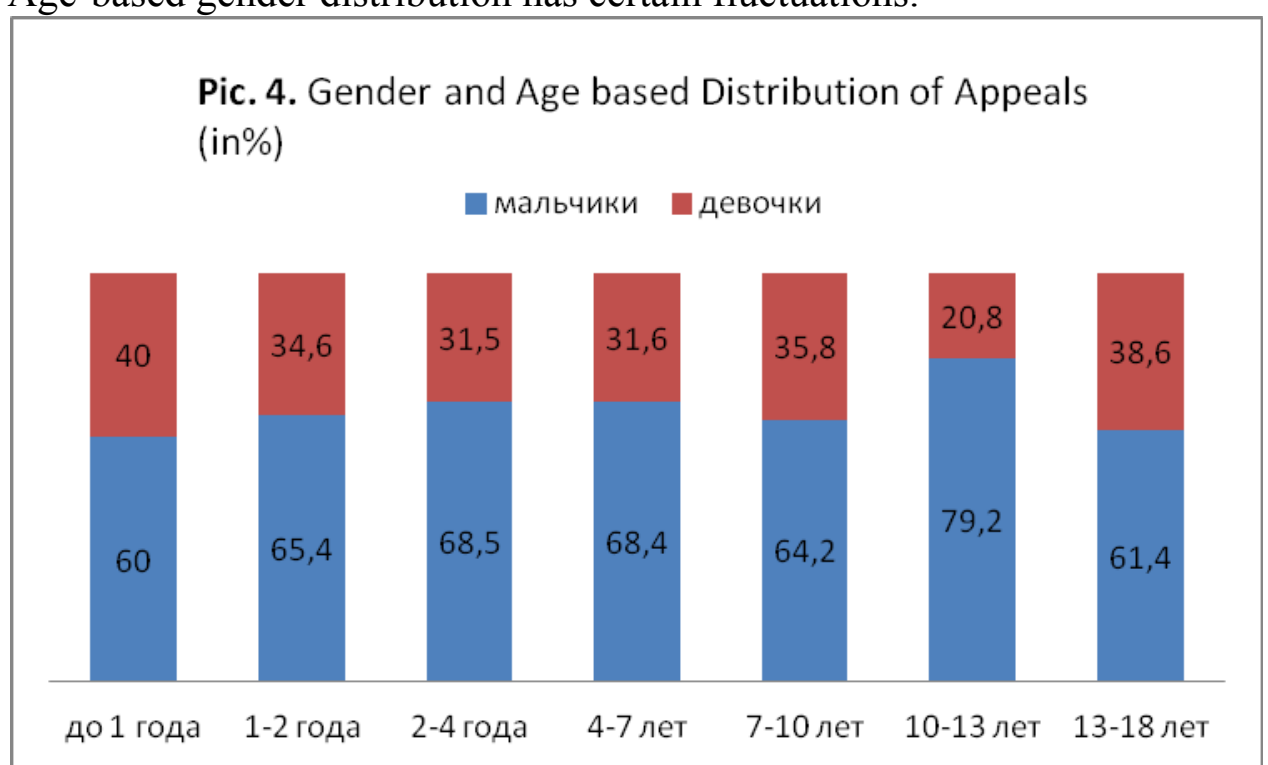

The boys to girls ratio is close to equilibrium in the $<1$ age group, which is apparently due to the above mentioned prophylaxis-purposed appeals. Further on, boys' appeals account for a greater\%age that peaks at 10 to 13 year. It is obvious that at this age, the proportion of more severe chronic pathology increases, which is reflected in the gender distribution. However, the adolescence is characterized by increase in the number of girls' appeals. This may be due to the manifestation of ANS conditions at this age, such conditions associated with the endocrine, emotion and personality alterations that occur more often in girls.

The following analysis proves the gender-based specifics of different neuropathology types (pic. 5).

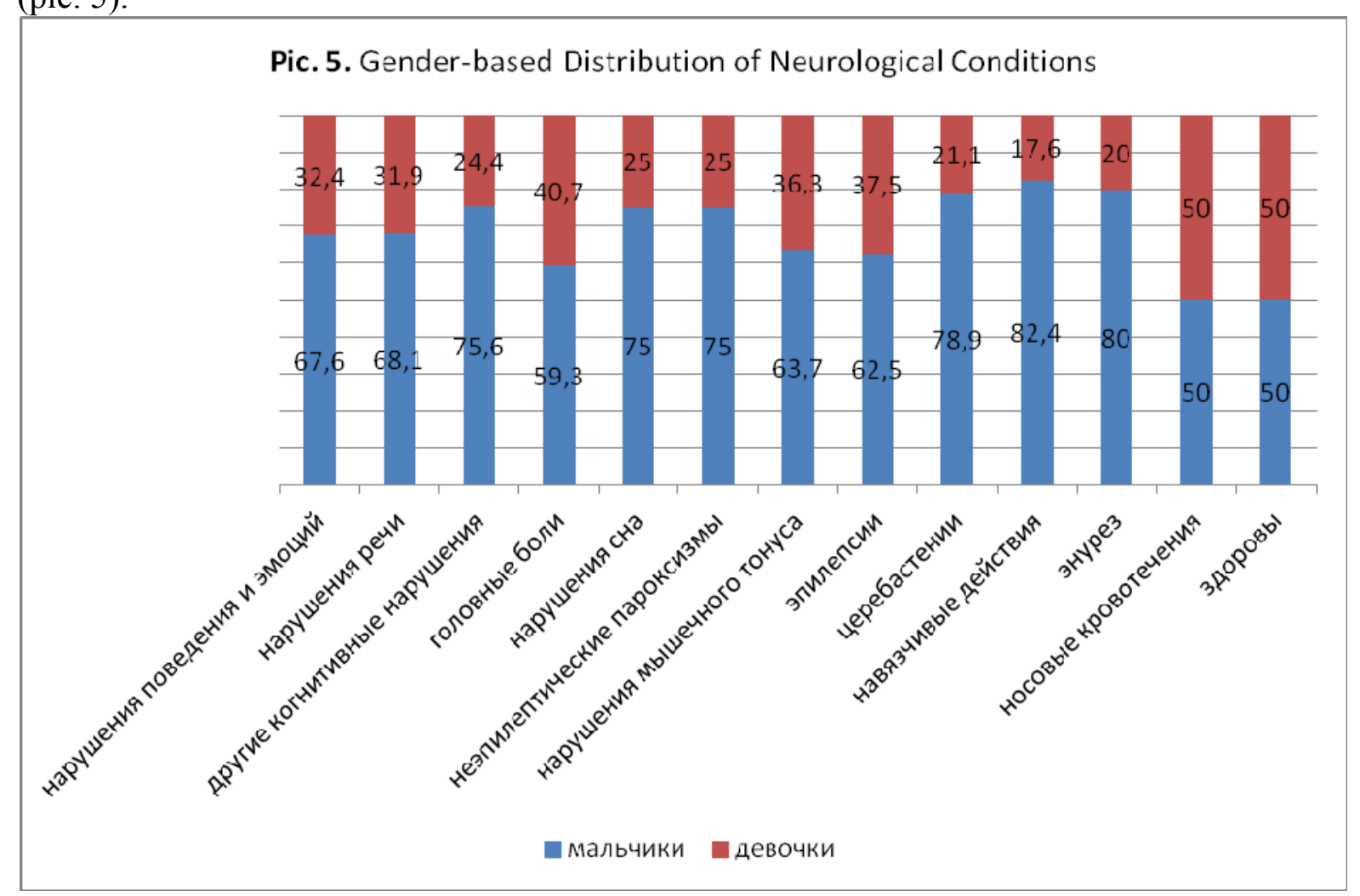


In boys, the most frequent manifestations are those of cognitive disorders, sleep disorders, nonepileptic paroxysms, encephalasthenia, obsessive-compulsive disorders, and enuresis. For girls, the most typical disorders are headaches and epistaxis. These conditions, either alone or as a part of dysautonomia, are closely connected to emotions and endocrine alterations responsible for such gender-based peculiarities.

Therefore, the gender-based appeal ratio has certain age-related specifics dependent on whether it is a prophylaxis-purposed or a treatment-purposed appeal as well as on the neuropathology type.

\section{Neuropsychological Disorder Distribution}

For the health service provision administration, the outpatient care neuropsychological disorder distribution is of great interest, which is why we have analyzed the initial appeals per different morbid conditions. When analyzing the results, it should be borne in mind that one appeal may be related to several neuropathology types.

First, we have grouped the pathologies into disorder-based groups that reflect disorders of different NS functional units (pic. 6). This should help emphasize certain points in outpatient care organization, train neurologists, and approach their specialization properly.

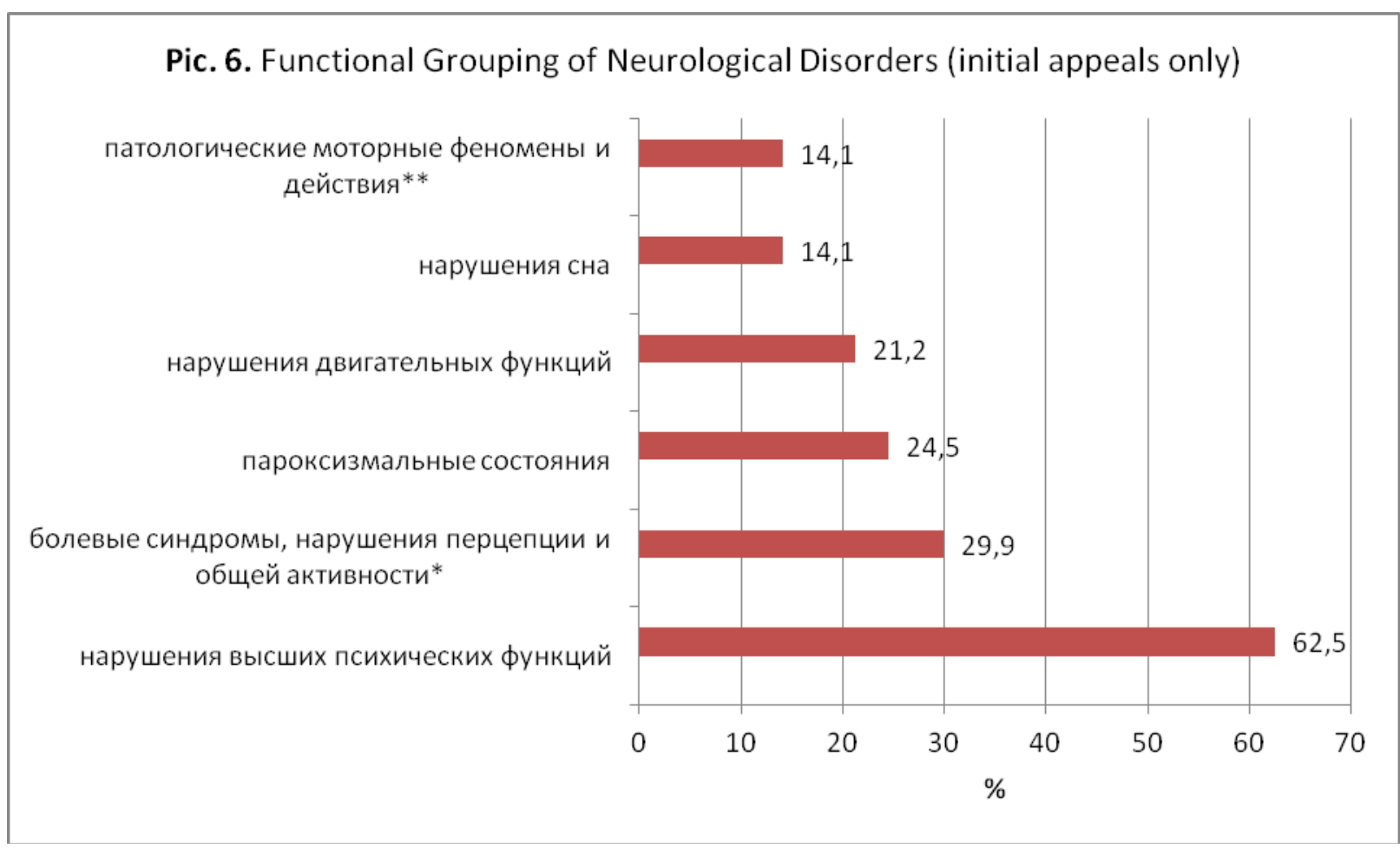

Note. * - incl. headaches, dizziness, and encephalasthenia; ** — including tic disorders, stuttering, enuresis, and compulsive movement disorders.

Higher mental performance disorders are the most frequent causes for initial outpatient appeals to neurologists. Having summarized the data whilst taking into account the comorbidity, i.e. the combination of several disorder types in one child, we have found out that certain mental disorders were identified in $62.5 \%$ of initially appealing patients, which makes for a pole position in this group-based neurological disorder distribution.

Below are the data on certain neuropsychological disorders (pic. 7).

The most frequent of those are behavior and emotion disorders accounting for almost $40 \%$ of all the cases. These conditions include neurasthenia, hyperactivity behavior disorders, adjustment disorder, phobic anxiety disorder in children, family-limited behavior disorder, social anxiety disorder in children, characterological and pathocharacterological responses, etc. The frequency of such disorders is first and foremost caused by emotional disorders reflecting the lack of the 
child's motif and wish actualization, whilst behavior remains an integral act of psychics which consolidates all the components of the mental process. Therefore, any long-term pathology of the higher NS units as well as lack of motif actualization is what causes the disorders of this this group. Looking from a different angle, the higher frequency of these disorders is conditioned by their specifics. The genesis of emotion and behavior disorders is formed not only by the biological factors like genetics, hypoxia, injuries, etc., which are common for any pathology, but also by social factors like child and parent relationships, pedagogical influence, impact of the family, of the school and other social institutes [4,5].

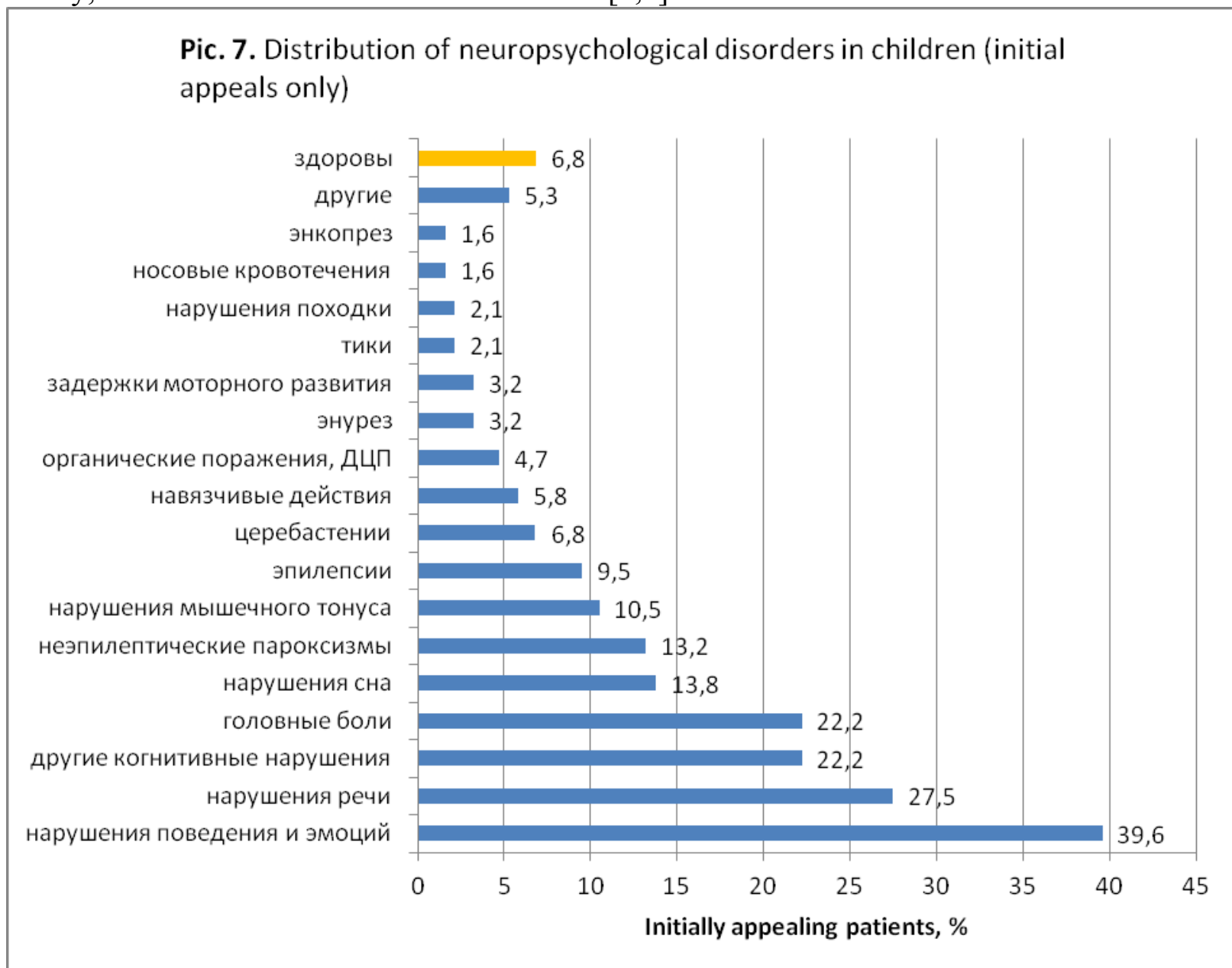

It is well-known that in Russia, most of the initial appeals related to behavioral issues are directed to pediatric neurologists, which is especially true for toddlers and preschool children, whilst psychiatrists receive only a small number of initial appeals. That is why it shall be noted that newly trained pediatric neurologists shall be better prepared to diagnose locomotor disorders and paroxysmal phenomena. From our experience, we can say that in-depth diagnostics of such conditions by neurologists involving psychologists and speech therapists is a rare case $[4,6]$. However, the problem is being underestimated not only by neurologists, but also by parents. Thus, the pic. 8 shows that the behavior and emotion disorders are the most underestimated problem related to the initial appeals. In one third of all the cases, parents do not complain of these disorders. The second most frequent group accounting for $27 \%$ comprises speech disorders, i.e. delayed speech development, expressive and impressive speech disorders, dyslexia, stuttering, etc. See pic. 8. The speech disorders are prevalent in children and are a serious problem, an inappropriate solution of which inescapably results in social sequelae and personality disorders $[4,5,7,8]$. However, this group is also often underestimated by parents in almost $24 \%$ of all the cases. See pic. 8 . 


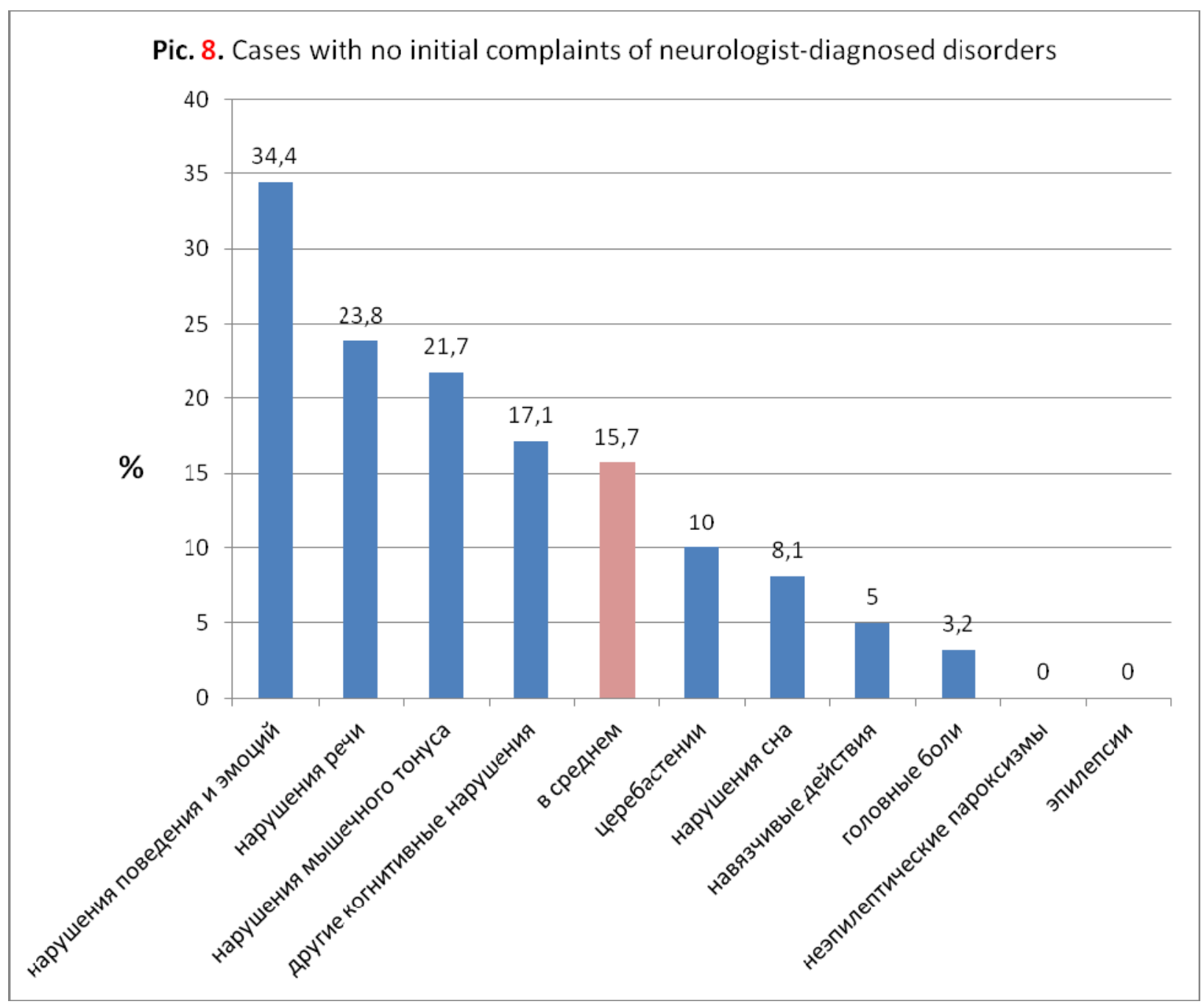

In $22 \%$ of all the cases, other disorders were identified in addition to speech disorders. Those included developmental delay, attention deficit disorder, partial cognitive deficit, and mild cognitive disorder. Intellectual disability and autism were noted in several cases only. Therefore, most of the disorders are initially non-severe cognitive disorders. This group is also subject to parents' underestimation, although not that often (in $17 \%$ of all the cases). The age-based distribution of underestimation is similar to that of speech disorders, as children younger than four years account for most underestimation cases.

$22 \%$ of the appealing patients suffered from headaches, which headaches being the most frequent non-psychic pathological conditions. Parents like to emphasize such disorders, as the latter are specified in $97 \%$ of all the complaints of the older age groups. Parents of preschool children even emphasized non-existent headache in children with a strong imagination.

Sleep disorders were identified in $13.8 \%$ of initial appeals. This group is as much topical as it is ambiguous in terms of diagnostics. It is heterogeneous, as it includes processes of different origins from apnea and insomnia to somniloquence and nightmares. Based on the clinical logic, it should be referred to not as sleep disorders, but as sleep time disorders. A difficult issue consists in defining what phenomena and sleep time events shall be considered clinical pathologies, i.e. cases with consequent impact on the person's physical and psychic well-being. This applies to somniloquence, middle-of-the-night awakening, the so-called benign myoclonus, nightmares, etc. The final statistics may vary based on the interpretation of such episodes. Due to this, the question of the real frequency of such disorders remains open.

Conventionally, paroxysmal epileptic and non-epileptic disorders remain an important reason for appealing to the neurologist. In total, they occurred in $24.5 \%$ of the initially appealing patients. Most of paroxysmal conditions of both types are the subject matter of outpatient neurology and 
are evenly distributed among all the age groups. Care for epileptic patients is well-organized, and parents are well-informed, which is the reason why follow-up attendances are so frequent (pic. 9).

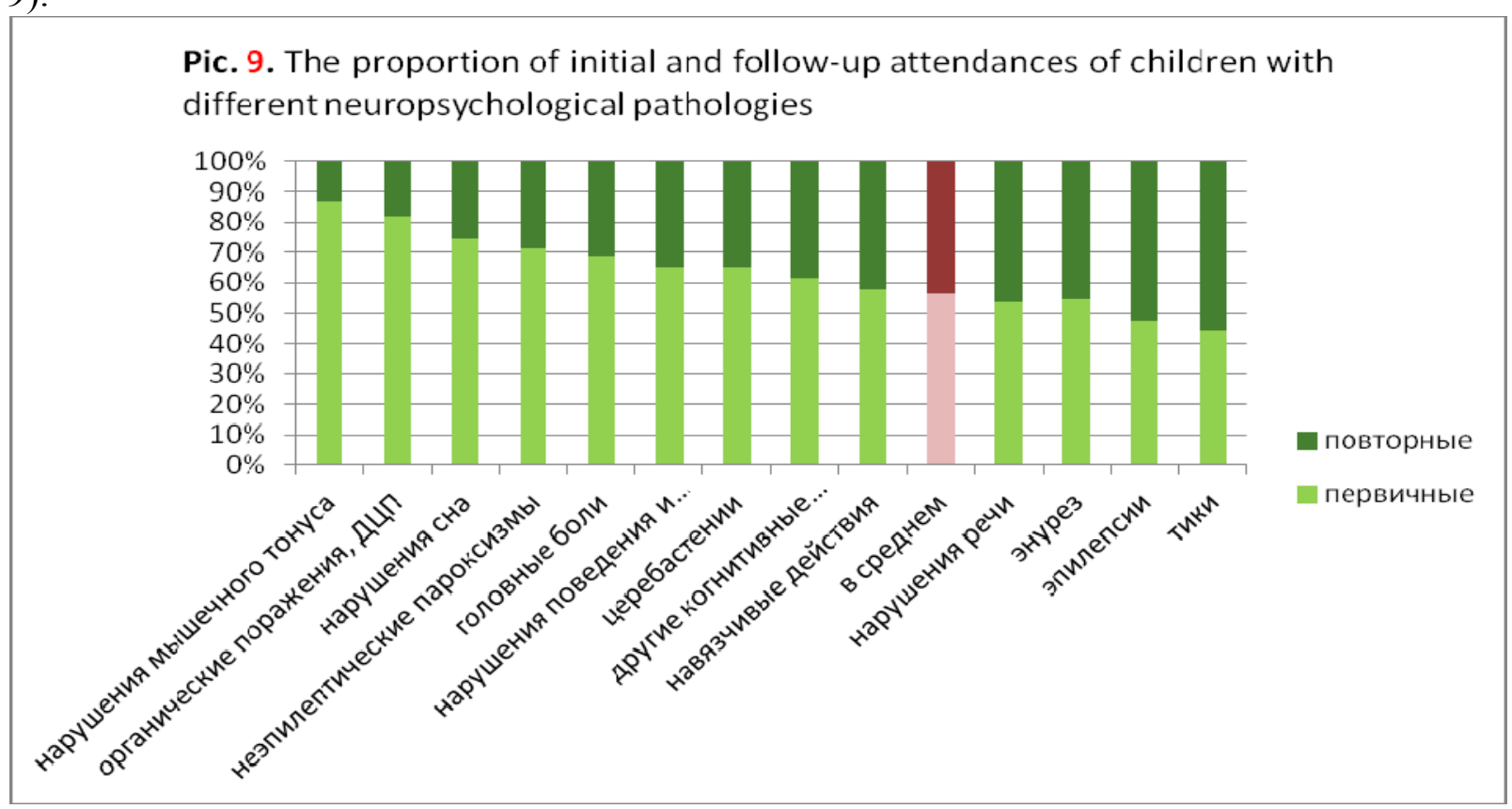

It is commonly known that neurological disorders are extremely diverse. In addition to the above mentioned pathology types, ten others are identified in 1 to $10 \%$ of all initial appeals to pediatric neurologists. Those include organic lesions of the CNS, encephalasthenia, muscular dystonia, tic disorders, enuresis, etc. Rarer conditions are grouped into the Other category.

The appeal distribution depends on the age. In $<7$ age groups, all the higher mental performance disorders prevail, especially speech disorders. In 7-10-year-old patients, speech disorders and other cognitive disorders do not outperform other topical neurological conditions in terms of frequency, and they are even less frequent in over-10 children. In patients younger than ten years, emotion and behavior disorders are still most frequent; however, in older patients they are less frequent than headaches. It is obvious that the decrease of the frequency of speech disorders and other cognitive disorders in over- 7 patients is related to the fact that some $50 \%$ of those are compensated and therefore become less topical. The pole position of the disorder distribution in over-10 children is occupied by the headaches (pic. 10). It is commonly known that tension headaches are prevalent in children and are mostly provoked by emotional stresses and cognitive loads. Therefore, we can say that in over-10 children, direct manifestations of cognitive and behavioral disorders become less frequent, and the lead position is taken by the symptoms of physical ill-being associated with the cognitive and emotional functions. Paroxysmal conditions are quite evenly distributed between all the age groups.

Attention shall be given to the presence of healthy patients in the initial appeal distribution. Thereby, $10.9 \%$ of parents had no specific complaints. This once again proves the fact that outpatient neurological care handles not only treatment-purposed, but also at prophylaxis-purposed appeals. 


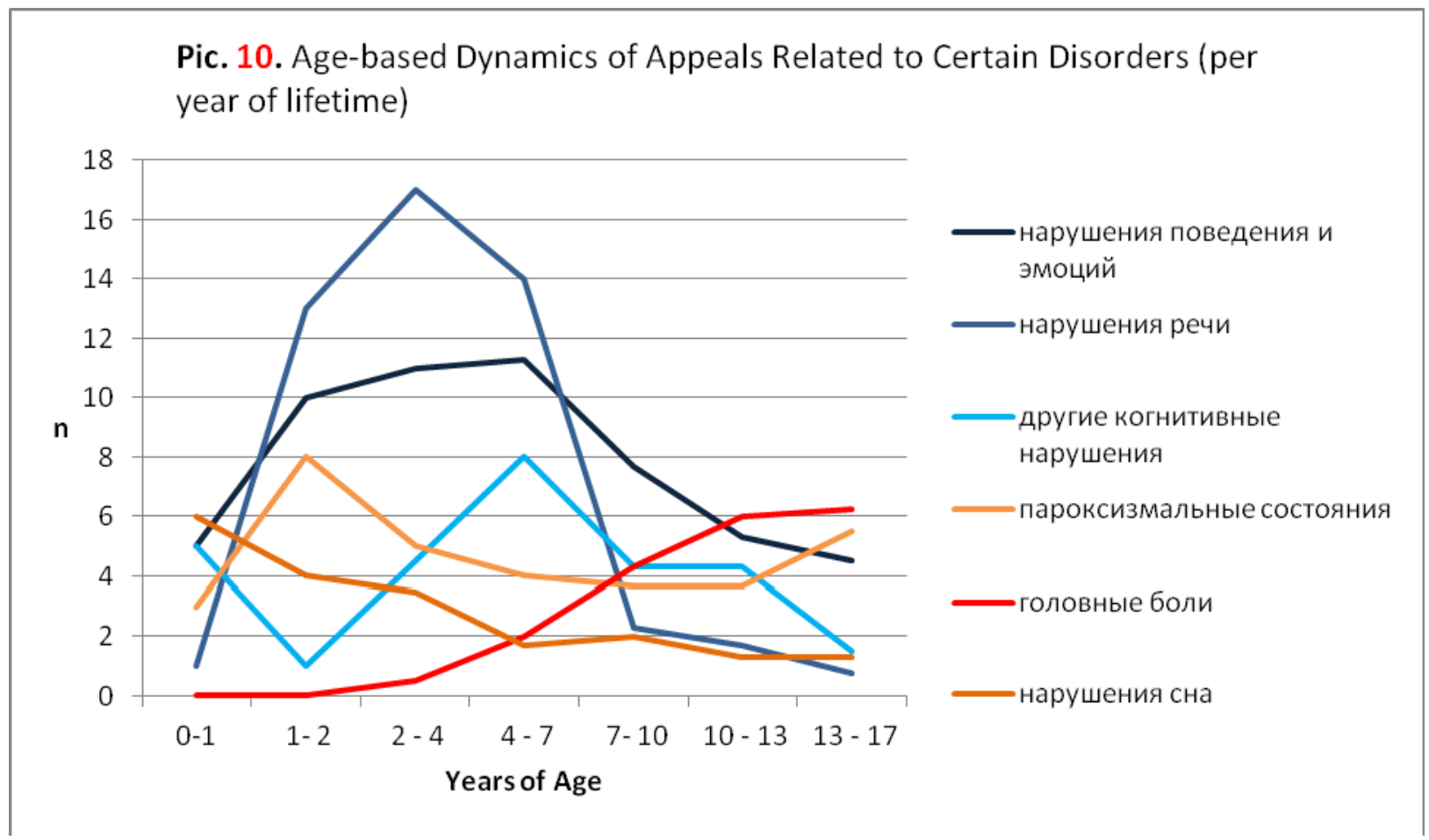

\section{Comorbidity of Neuropsychological Disorders.}

The above mentioned data show that one patient may simultaneously have several pathologies. In $72.7 \%$ of all the cases, neuropsychiatric pathologies of several types were identified in one patient at a same time. Therefore, the outpatient neurologic pathology in children is highly comorbid. Clinical pattern of different neuropsychological disorders has also been analyzed (pic. $11)$.

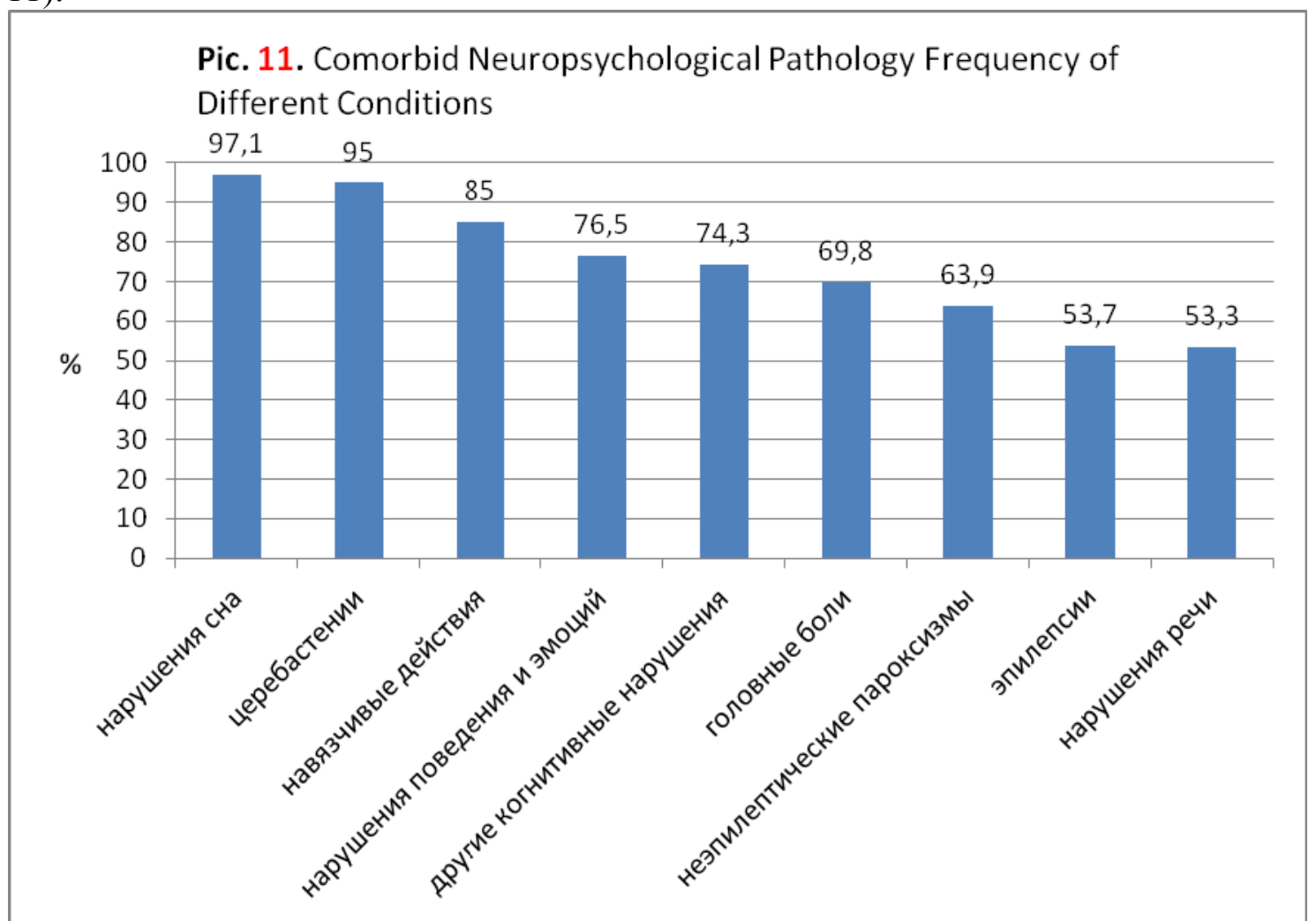

The most comorbid are sleep disorders. This once again proves that within the conventional disorder group, pathogenetically and clinically heterogeneous conditions are found, many of which do not have any primary specifics. It is reflected by the high proportion of another neurological pathology combined therewith. 
The high comorbidity of encephalasthenia can be considered conditional, as we have identified headaches as individual conditions due to classificatory peculiarities, although they shall be taken into account as encephalasthenia manifestations, not as comorbid conditions. Since the headaches, according to our data, have accounted for more than a half in the encephalasthenia comorbidity distribution, the real pattern of the organic psycho-syndrome shall be recognized an order of magnitude lower than $95 \%$.

Epilepsy and speech disorders have moderate concomitant symptoms, just above $50 \%$. This indicates that these conditions are more apparently specific, are primary and do not depend that much on the totality of the anatomical and functional NS disorders. Epileptic activity is a specific form of neuronal activity and may be limited to paroxysmal phenomena without affecting the basic brain functions. It is commonly known that idiopathic, i.e. primary and benign epilepsies account for up to $30 \%$ of all epilepsies. It is obvious that outpatient care registers a lot more idiopathic epilepsies. In our group, idiopathic epilepsies accounted for $48.8 \%$, which determined their low comorbidity.

The speech function is based on the high and the most sophisticated anatomical and functional level of neuronal interaction. It also depends on the social factors, which is why its pathology may develop independently without any other higher mental performance disorders. The relatively isolated position of the speech disorders is confirmed by the fact that the distribution of their comorbid conditions (pic. 12) is dominated by behavioral and emotional disorders as well as by other cognitive disorders of the related higher mental functions while the pathology of other functional brain areas is hardly to be found. A similar distribution of additional clinical symptoms is also characteristic of other cognitive disorders.

On the contrary, behavior and emotion disorders are comorbid with a diverse range of conditions. This may be due to the fact that emotional disorders are often complicated and manifest themselves via other functional brain areas in form of sleep disorders, headaches, tic disorders, compulsory movement disorders, etc.

Headaches are often comorbid with behavior and emotion disorders, encephalasthenia; this proves the fact that they depend on the emotional and general mental exhaustion. They are also often comorbid with paroxysmal conditions, mostly non-epileptic, which may be caused by their co-association with autonomous nervous system disorders.

In more than half of the cases, sleep disorders are comorbid with behavior and emotion disorders. Based on this information, it is difficult to judge the nature of this relation, i.e. to define the primary disorder. However, the authors' experience proves that in most cases, emotion and behavior disorders are primary. However, a special study is required to find the final answer.

\section{Pic. 12. Comorbidity Distribution for Different Pathological Conditions}

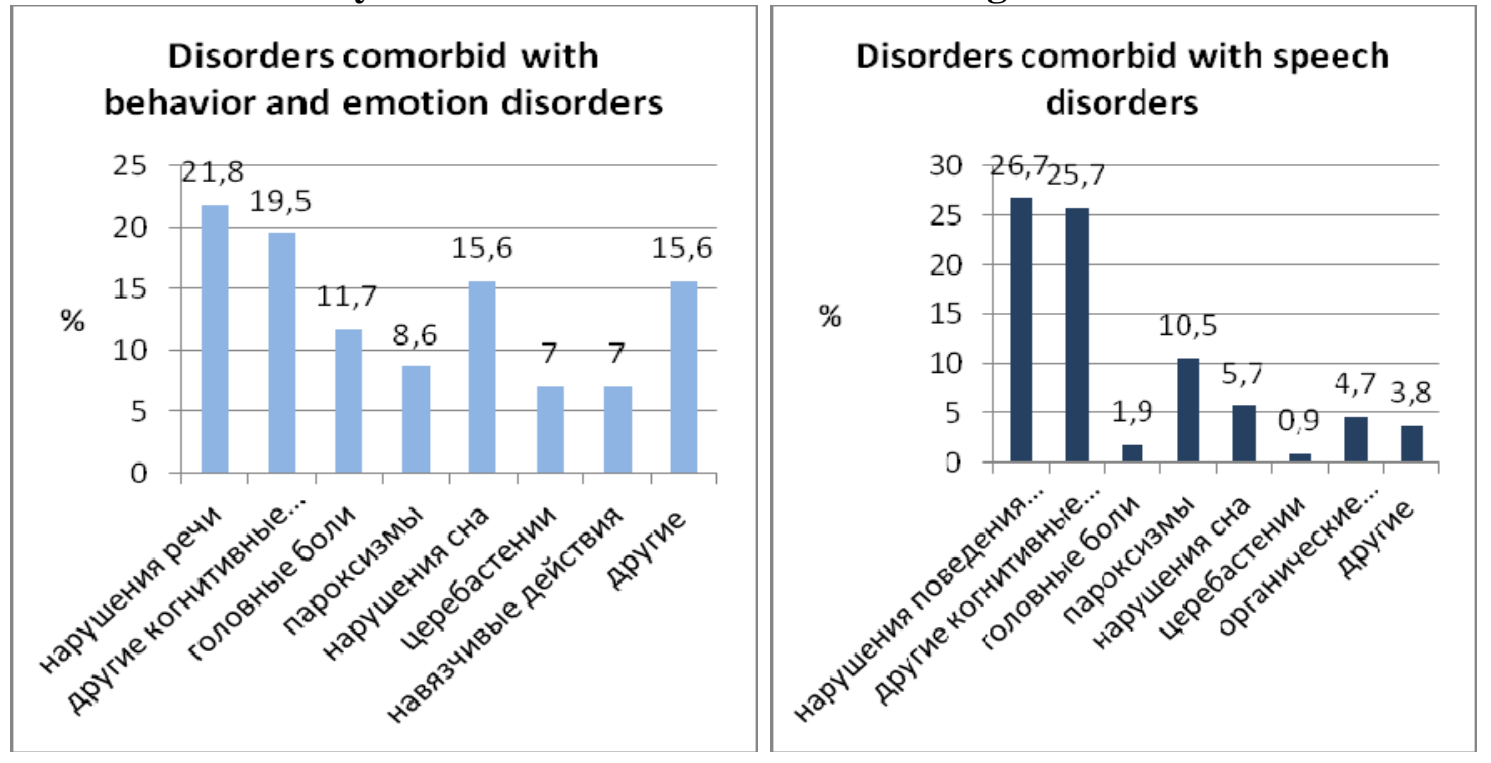




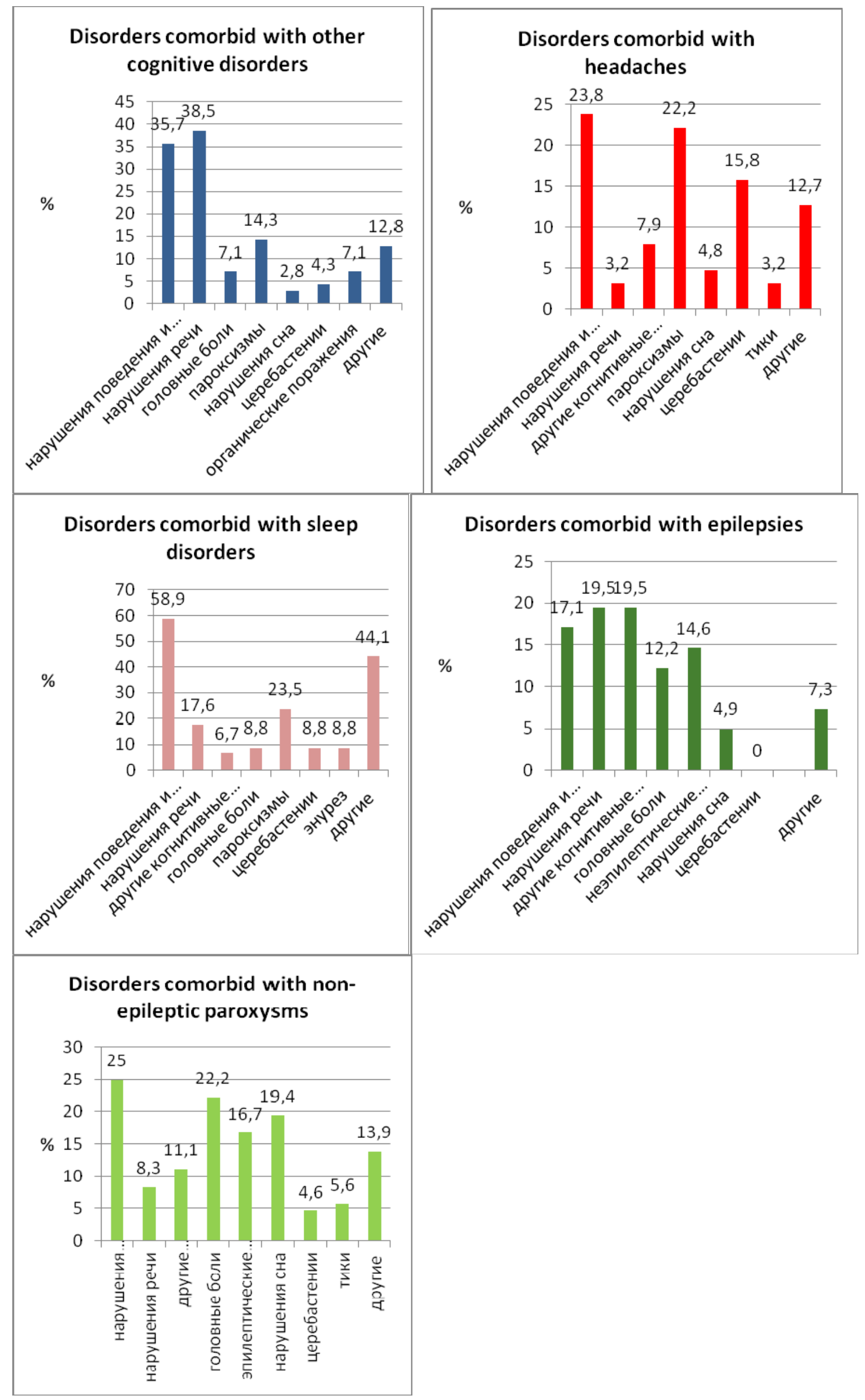




\section{Parents Underestimate Certain Pathological Conditions}

In this study, we have also analyzed the correspondence of the parents' complaints to the doctor's final diagnosis. It enables us to make conclusions on how adequately parents attach importance to certain disorders by the time of the first appeal.

As already mentioned, the most underestimated issue is behavior and emotion disorders. Usually, when parents complain of headaches and ANS symptoms in older children, they do not mention concomitant anxiety and fears, which are often the primary issue in such situations. In younger children, underestimated are the issues of the child's pathological attachment to the parents, inappropriate interaction between children and parents, and restlessness. Disorders of kindergarten and school adjustment are also often to remain out of sight. An additional analysis (see pic. 13) shows that this disorder group is underestimated in all over-2 patients, as the behavior of a 2-year-old child can be differentiated by the physician. Underestimation peaks at the preschool age of 4 to 7 years. Apparently, it is due to the parents of such children not paying attention to the behavior and emotions, though they are clear for the physician. Without a doubt, the parents' and the physician's insufficient realization of the problem are interrelated. On the one hand, absence of complaints excludes behavioral disorders from the diagnostic search when carried out under the circumstances of a shortened outpatient attendance. On the other hand, if an issue is not attached importance to in the health care system, parents will not pay attention to this type of disorders.

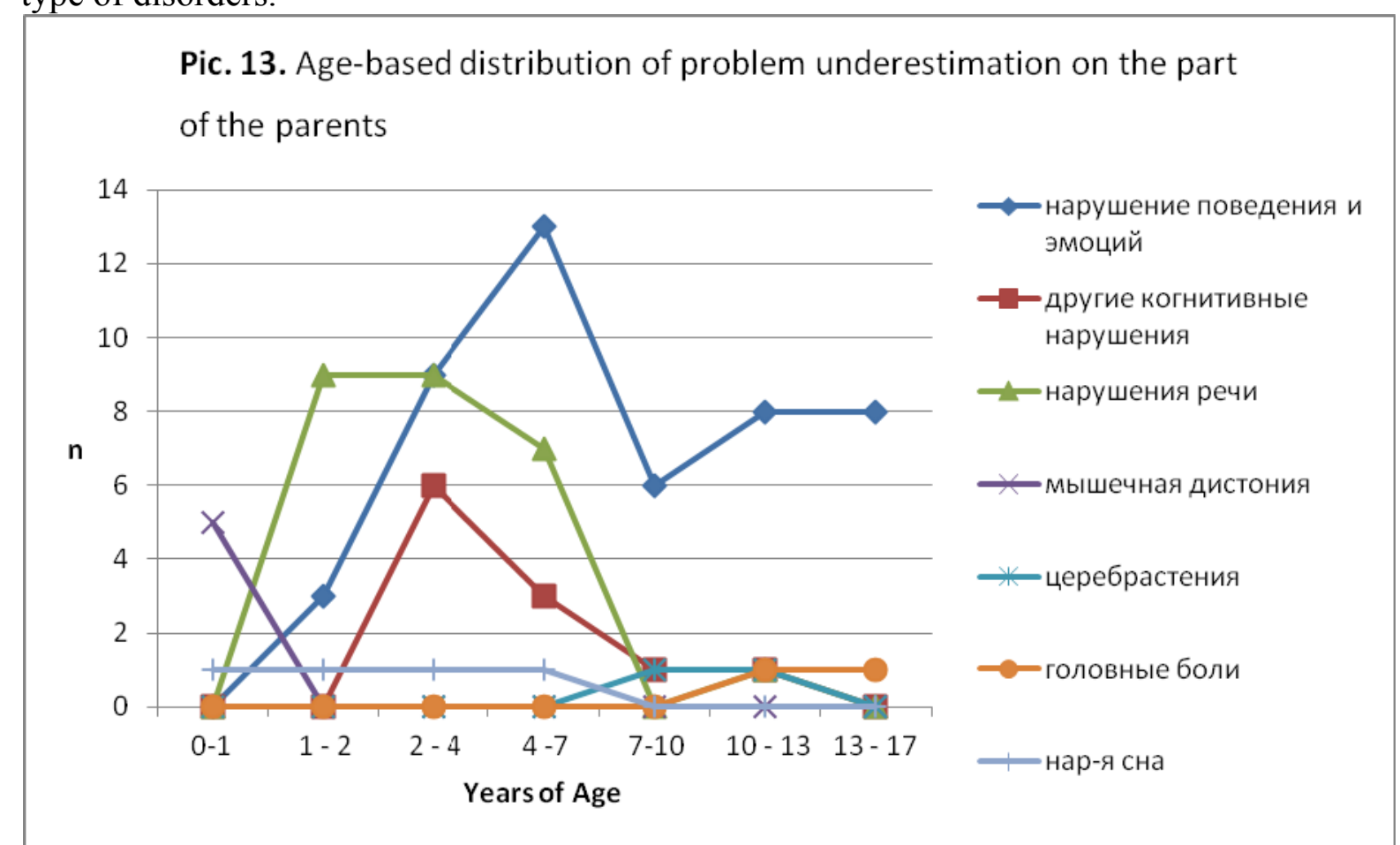

Speech disorders are underestimated almost as often (in $24 \%$ of all the cases). This mainly concerns the 3-4-year-old group, not to mention the $<2$ group, and manifests itself in the form of underestimation of speech underdevelopment. Parents irresponsibly count on a boosted speech development and as a rule refer to the unique examples of such positive outcomes among friends. See pic. 13. Generally, underestimation of speech disorders in children younger than four years was identified in $72 \%$ of all the cases. Meanwhile, it is commonly known that based on the specifics of cognitive function formation, the effectiveness of treating such conditions is directly dependent on the treatment start timings.

Other cognitive disorders are often left out of account in 2-4-year-old children. However, physicians are able to diagnose such conditions properly in children of this age, whilst in children younger than two years, mild cognitive disorders are not apparent for the neurologists. Therefore, the age peaks we have obtained do not always represent the reality, as in some 
situations, they display not just difference in parental approaches, but also diagnostic differences. Obviously, it a doctor cannot accurately diagnose a mild cognitive disorder in an 18-month-old child, it does not ensure any lack of such disorder. Accordingly, the parental underestimation concerning such children will be no lower than concerning older children.

It is difficult to accuse parents of underestimating muscular dystonia in younger-than-a-year children, since non-specialists can rarely identify it. However, we have decided to keep this parameter due to our ideological considerations. It is commonly known that muscular dystonia in younger-than-a-year children are an overdiagnosed phenomenon, largely due to the subjectivity of muscle tone measurement and estimation techniques as well as the short duration of outpatient attendance. Combined with the variability of the child's muscle tone, these factors condition the physician's failure. In such a situation, diagnostics shall be bound to other factors to a maximum extent. The severity of disorder manifestations that can be noticed by parents may serve as such a factor, as it can indicate an apparent muscle tone disorder and the permanence of its manifestations.

\section{DISCUSSION}

On the one hand, the results of the study reflect the fundamental processes of forming, alteration and pathologization of the child's NS. On the other hand, they test the impact of how pediatric neurologic outpatient care for children is organized, in some aspects. In accordance therewith, the conclusions of experts shall concern the appropriateness of the current specialized outpatient care organization given the neurologic disorder prevalence trends.

The study is limited in terms of estimation and interpretation, partially due to its being carried out within Moscow and Moscow region limits. The pediatric population of Moscow experiences an especially intense human-induced impact, social and environmental stresses, which are first and foremost due to the conditions of the largest metropolitan area of the country as well as due to the concentration of the population determined to be economically and socially successful. Therefore, care should be taken when extrapolating the results of the study on a national scale. It is of utmost importance to exclude territories with rural and smaller urban population from comparison. The other limitation is due to the peculiarities of diagnosing neuropsychological disorders in Russia. There are no standardized technique for diagnosing certain sleep, behavior and emotion disorders, cognitive disorders, muscular dystonia, and others, which is why the results of this study may be different from those of other observations or personal experiences of some experts. In such situations, the objectivity of the data is called into question. However, the discrepancies may and should be the subject matter of the debates, which is therefore to be recognized as another result of this work.

The analysis of the age dynamics shows that the number of appeals is reduced with aging. Taking into account the follow-up appeals, it is most likely an evidence that parents turn over from prophylaxis-purposed appeals to treatment-purposed appeals. The fact that the prophylaxispurposed appeals among parents of toddlers stand out in terms of numbers may be due to a set of factors:

1) importance attached to preventive medical examinations and prophylactic approaches that is characteristic of pediatrics in Russia:

2) active immunization;

3) mother's anxiety about younger children's health;

4) physiology of the younger child's CNS that makes their behavior difficult for parents to interpret.

However, the prophylactic appeals may also mean that the primary care does not fully accomplish this mission. We remind you that $10.9 \%$ of parents had no complaints at all.

In general, the neurological pathology distribution comprises 17 different disorder classes with a frequency of $1+\%$, which shows a great diversity of conditions for the neurologist to handle. It shall be noted in relation thereto that the structure of the data presented in the Russian guidelines and textbooks does not correspond to the above-mentioned distribution. In scientific papers as 
well as at conferences, only certain conditions like epilepsy, multiple sclerosis, attention deficit disorder, rare conditions, etc. are covered, but we cannot say that the entire topical spectrum is presented to an appropriate extent $[4,9,10]$. This inescapably results in an insufficient training of personnel to work at the mentioned health care units, although it is the outpatient care that handles most neurological cases.

The neurological conditions feature a high comorbidity, as in $72 \%$ of all the cases, several disorders are simultaneously observed in one patient. This determines the high intensity of the neurologist's work who also has to cope with the limited attendance timing. Combined with pathological diversity, this factor enables us to state the basic requirements for the neurologist's performance. They shall therefore be able to identify the main patterns of pathogenesis and clinical manifestations of different disorders quickly, but appropriately, as well as to define how they interact. Such performance involves extensive experience, ability to think over a broad spectrum of conditions simultaneously and in an algorithmic manner, ability to vary the attendance technique based on the clinical situation, i.e. to switch between checkup, questioning and simple conversation. We think that attention should be given to the suggested requirements when training the specialists of this major.

The functional distribution of neurologic disorders is dominated by disorders of higher mental performance that are identified in $62.5 \%$ of all children. Such disorders are two to four times more frequent than other disorders, including pain syndromes, locomotor disorders, and paroxysmal conditions. This is discordant with the current situation in terms of training neurologists and covering the neurology issues, since it is commonly known that more attention is given to locomotor and paroxysmal disorders [9-12]. After the Neuropsychology major was formally abolished in the 1970s, there has arisen a tendency of locomotor and sensorium disorders being considered the primary area of interest for neurology. As the neurology "drifted" on the one hand, and the psychiatry focused on autism, schizophrenia, intellectual disability, and depression on the other hand, a large group of mild cognitive and emotion disorders has been left on the periphery of specialists' attention. Meanwhile, the parents with complaints of such disorders tend to visit pediatric neurologists due to inertia and some other reasons [4]. As mentioned above, pediatric neurologists are mostly focused on diagnosing and treating locomotor disorders. Cognitive and behavior disorders are only handled by a small group of specialists.

The results of the study show that currently, psychiatric disorders prevail in the outpatient practice of pediatric neurologists. This calls into question the importance attached to the topic of higher mental performance disorders in pediatric outpatient neurology as well as shifting the focus in terms of specialist training. First and foremost, it concerns behavior and emotion disorders that account for almost $40 \%$ of the pathology distribution in the pediatric outpatient neurology, such disorders including neurasthenia, neurotic reactions, hyperactivity behavior disorders, phobic anxiety disorders in children, family-limited behavior disorder, pathocharacterological and characterological responses, etc. According to our data, errors in managing patients with such disorders are noted in $42.8 \%$ of all the cases, not to mention the fact that most neurologists are not ready to lead integrated teams involving psychologists and speech therapists unless such work is limited to simple authorization of conclusions. In addition, parents do not always complain of emotional and behavioral disorders. Based on the results of this study, they only do so in $34 \%$ of all the cases. This indicates that the problem is underestimated on the part of the health care system, as the parental suspicion in regard to this or that pathology depends on how well they are informed via conversations with physicians, interviews and papers published in popular science media, visual materials at medical centers, etc. Underestimation of such conditions may result in forming disordered personality with all its socially significant consequences as well as in a wide range of neurological and psychosomatic complications accompanying it.

Another common $(27.5 \%)$ but underestimated by parents $(24 \%)$ problem is speech disorders. Although our data show that speech disorder numbers peak at the age of 2-4 years, it makes 
sense to address the estimation limitations. At most outpatient care units, pediatric neurologists diagnose speech disorders in a manner different from ours, which as a rule results in an inescapable diagnosis delay; thus, the peak numbers are only reached at the age of four to six years. According to our data, $72 \%$ of parents notice the speech disorders in children younger than four years. Leaving implicit organizational issues alone, we can say that diagnosing delays follows the above-mentioned fact. Speech disorders are the most common cause of children's academic underachievement and social deadaptation. Taking into account the results of the study, the topical issue is emphasizing wide-scale diagnostics in regard to such disorders in 1-3year-old children, since the timing of treatment inception determines the treatment success.

The same applies to a range of other cognitive disorders including developmental delay, attention deficit disorder, partial cognitive deficit, and mild cognitive disorder. Those are identified in $22 \%$ of all the cases and are often underestimated by parents of children younger than four years. The problems of mild cognitive disorders are similar to those of speech disorders which proves their comorbidity. Therefore, it make sense to speak of a set of speech disorders and other cognitive disorders in terms of care organization.

The fact that there are less registered speech disorders and other cognitive disorders in school pupils should be considered a phenomenon caused by compensation of such disorders in half of all the cases. However, they can transform into other neurological symptoms or their complications may manifest themselves at this age, which seems plausible as well. Analyzing the distributions of pathological conditions with regard to knowledge of their genesis has provided the results that allow for the following statement: after the age of 7 to 10 , the direct symptoms of higher mental performance disorders are replaced by indirect manifestations like headaches, tic disorders and obsessive-compulsive disorders. Great combinability of those symptoms with behavior and emotion disorders proves the above statement. Neurologists shall take into consideration the psychological and emotional component as the prime pathogenetic factor determining the development of headaches, tic disorders, sleep disorders, and obsessivecompulsory disorders when diagnosing and treating the latter. This is an issue foregrounded by the above-mentioned patterns.

Sleep disorders are a specific issue of pediatric neurology. The results of our study indicate that there are still theory and definition issues that call into question the specificity of uniting all the sleep-related disorders into a single group, as it is usually done. It is no coincidence that for the conventionally defined sleep disorders, the comorbidity level was almost $100 \%$. In $58 \%$ of all the cases, such disorders are associated with behavior and emotion disorders, which also draws attention. The main points of the discussion that arise from analyzing the results of the study and our experience are as follows:

1) finding out whether certain sleep disorders are primary or secondary, whether they are nosologically independent;

2) identifying the proportion of certain sleep disorders and the criteria for their verification,

3 ) determining pathogenetic and clinic heterogeneity of the conditions that are traditionally grouped as sleep disorders.

It seems to us that a large number of questions and contradictions is due to grouping these disorders. The fact that unusual symptoms are often observed during sleep time does not substantiate that they are related. If you stick to such principles, you shall also group all the diseases manifesting themselves during wakefulness, but it is clear for everyone that the etiology and the manifestations of such conditions are multifaceted in a way that renders such grouping senseless.

The results of studies on paroxysmal (non-)epileptic conditions give ammunition to the idea that they represent an issue of utmost importance for pediatric neurology, an issue severely underestimated by parents of children of all age groups. Note that epileptic and non-epileptic paroxysmal conditions are not related (which is proved by this study) and do display high levels of intercombinability. For instance, only in $14 \%$ of all epilepsy cases, comorbid non-epileptic 
paroxysms were identified. The only (but important) reason to group them together is the need for differential diagnostics that can help differentiate them.

\section{CONCLUSIONS AND RECOMMENDATIONS}

1. It is imperative to provide for special training and re-training of neurologists to work at outpatient specialized care units, as such specialists require specific skills for working under set conditions.

2. Information contained in textbooks and guidelines on general neurology shall be revised and restructured to reflect the actual wide-scale statistics on neuropathology properly. Given the expansiveness of data thereon, it is imperative to issue separate guidelines for outpatient pediatric neurologists.

3. A set of organizational measures shall be implemented to foreground diagnosing higher mental performance disorders by pediatric neurologists, such measures comprising training and re-training specialists, information distribution, organizational and methodological work.

4. Besides, it is imperative to take a set of measures aimed at enhancing the physicians' ability to diagnose speech disorders and other cognitive disorders in younger-than-three children. 5. When diagnosing and treating headaches, tic disorders, obsessive-compulsive disorders, and sleep time disorders, specialists shall take into consideration the fact that the psychological and emotional component is the primary contributor to the genesis of such conditions.

6. It shall be discussed whether the sleep disorder grouping generally accepted in pediatric neurology is compliant with the clinical principles, such discussions being further subject to publishing.

\section{CONCLUSION}

The outcomes of the study raise a number of organizational questions as well as clinical and theoretical questions. Certain methodological limitations and the evaluative nature of certain provisions, findings and conclusions render the study subject to discussion. The topics that the study foregrounds shall be further researched in other publications and developed in reports in media and at business meetings of organizers and leading pediatric neurologists.

\section{CONFLICT OF INTEREST}

The authors have indicated they have no financial relationships relevant to this article to disclose.

\section{REFERENCES}

1. Baranov A.A., Namazova-Baranova L.S., Altunin V.V., Al'bitskii V.Yu., Aslamazyan L.K., Akhmedullina D.I., Batyrova Z.K., Belyaeva I.A., Borovik T.E., Buslaeva G.N., Bushueva T.V., Vashakmadze N.D., Vinyarskaya I.V., Vishneva E.A., Galitskaya M.G., Gevor-kyan A.K., Gorelova Zh.Yu., Zorkin S.N., Ivanyushkin A.Ya., Ivardava M.I. et al. Profilakticheskaya pediatriya. Rukovodstvo dlya vrachei. Pod red. A. A. Baranova [Preventive Pediatrics. Guidelines for Doctors. Ed. by A.A. Baranov]. Moscow, Soyuz pediatrov Rossii, 2012.

2. Gavrilova T.A., Karkashadze G.A., Namazova L.S. Applying for a paid medical care in a consultative and diagnostic center of Moscow. Voprosy sovremennoi pediatrii $=$ Current Pediatrics. 2007; 6 (5): 22-23. 
3. Metodicheskie rekomendatsii po opredeleniyu moshchnosti ambulatorno-poliklinicheskoi pomoshchi Departamenta zdravookhraneniya g. Moskvy ot 12.09.1994 [Guidelines to determine the Power of Outpatient Care of the Department of Health in Moscow dated 09.12.1994].

4. Karkashadze G.A., Maslova O.I., Namazova-Baranova L.S. Actual problems of diagnosis and treatment of mild cognitive impairment in children. Pediatricheskaya farmakologiya $=$ Pediatric pharmacology. 2011;8 (5): 37-41.

5. Maslova O.I., Baranov A.A., Namazova-Baranova L.S., Karkashadze G.A., Mamed'yarov A.M., Lazarev M.L., Muradova O.I., Konstantinidi T.A., Anikin A.V., Kuzenkova L.M., Lazurenko S.B., Nemkova S.A., Il'in A.G. Modern aspects of the study of children's cognitive sphere. Pediatricheskaya farmakologiya = Pediatric pharmacology. 2012; 9 (6): $72-78$.

6. Gogberashvili T.Yu., Karkashadze G.A., Namazova-Baranova L.S., Maslova O.I. Neuropsychological methods in pediatrics: opportunities and prospects of application. Pediatricheskaya farmakologiya = Pediatric pharmacology. 2011; 8 (6): 83-87.

7. Kornev A.N. Narusheniya chteniya i pis'ma u detei: Uchebno-metodicheskoe posobie [Violations of Reading and Writing in Children: Study guide]. St. Petersburg, MiM, 1997. 286 p.

8. Zavadenko N.N., Kozlova E.V. Drug therapy for dysphasia development in children. Farmateka $=$ Pharmateca. 2013; 1 (254): 56-60.

9. Abramova M.F. et al. Klinicheskaya detskaya nevrologiya. Rukovodstvo dlya vrachei. Pod red. A.S. Petrukhina [Clinical Pediatric Neurology. Guidelines for Doctors. Edited by A.S. Petrukhin]. Moscow, 2008.

10. Guzeva V.I. et al. Rukovodstvo po detskoi nevrologii. Pod red. V.I. Guzevoi. Izd. 3-e, pererab. [Guidelines for Pediatric Neurology. Edited by V.I. Guzeva. $3^{\text {rd }}$ edition, revised]. Moscow, 2009.

11. Petrukhin A.S. Detskaya nevrologiya. Uchebnik dlya studentov uchrezhdenii vysshego professional'nogo obrazovaniya, obuchayushchikhsya po distsipline «Nervnye bolezni» po spetsial'nosti 060103.65 «Pediatriya» [Pediatric Neurology. Textbook for Students of Institutions of higher Professional Education on the Subject "Nervous Diseases", Specialization 060103.65 "Pediatrics"]. Moscow, 2009.

12. Badalyan L.O. Detskaya nevrologiya. Uchebnoe posobie dlya studentov uchrezhdenii vysshego professional'nogo obrazovaniya, obuchayushchikhsya po distsipline «Nervnye bolezni» po spetsial'nosti 060103.65 «Pediatriya». 3-e izd. [Pediatric Neurology. Guideline for Students of Institutions of higher Professional Education on the Subject "Nervous Diseases", Specialization 060103.65 "Pediatrics". $3^{\text {rd }}$ edition]. Moscow, 2010. 